\title{
P02.102. Evaluating the role of expectancy during stress-reducing aromatherapy in healthy older adults
}

\author{
I Fonareva ${ }^{1 *}$, M Demidenko², B Oken ${ }^{1}$ \\ From International Research Congress on Integrative Medicine and Health 2012 \\ Portland, Oregon, USA. 15-18 May 2012
}

\section{Purpose}

Aromatherapy is a common CAM approach for stress reduction, but its effectiveness and mechanisms remain unclear. It has been suggested that any stress-reducing benefits of aromatherapy are due to placebo (expectancy) effects. This study evaluates expectancy as a potential mechanism underlying stress-reducing aromatherapy actions.

\section{Methods}

To date, 54 participants (mean age $58.7,82 \%$ female) were randomized to either: 1 ) lavender (stress-reducing aroma), 2) coconut (detectable placebo), or 3) water (non-detectable placebo). The detectable placebo group was used to assess aroma-mediated expectancy. Further, half of the participants in each group, along with their aroma, received a prime suggesting they are inhaling a powerful stress-reducing aroma. The prime was used to evaluate verbally-mediated expectancy. Participants completed a visit during which they experienced the assigned aroma while undergoing a stress battery. Before and after the stress battery, we assessed participants' subjective stress-related measures, cognitive function, salivary stress biomarkers, and physiologic measures including EEG and ECG. ANOVAs were used to detect group differences with all outcomes reflecting post-stress percent change from baseline.

\section{Results}

Preliminary data show that, after the stress battery, there was no difference between the three aroma groups on subjective stress ratings and salivary cortisol and alpha amylase profiles (all p's $>0.1$ ). However, participants randomized to perceptible aromas (lavender and coconut), after stress battery, had decreased negative affect score on Positive and Negative Affect Scale compared to those randomized to water $(\mathrm{p}=.01)$. Further, though there was no effect of aroma on post-stress performance on cognitive tasks. Participants receiving a prime regardless of aroma group had smaller increases in median reaction time on Simple Reaction Time task, $\mathrm{p}=.01$. Expectancy and aroma effects on EEG and physiologic responses will also be discussed.

\section{Conclusion}

Preliminary data suggest that both aroma-mediated and verbally-mediated expectancy might be important in aromatherapy actions.

\section{Author details \\ ${ }^{1}$ Oregon Health \& Science University, Portland, USA. ${ }^{2}$ Portland State University, Portland, USA.}

Published: 12 June 2012

\section{doi:10.1186/1472-6882-12-S1-P158}

Cite this article as: Fonareva et al: P02.102. Evaluating the role of expectancy during stress-reducing aromatherapy in healthy older adults. BMC Complementary and Alternative Medicine 2012 12(Suppl 1): P158.

Oregon Health \& Science University, Portland, USA

Full list of author information is available at the end of the article 